\title{
Development of gyrotron traveling-wave tubes at IAP and GYCOM
}

\author{
S.V. Samsonov ${ }^{1}$, G.G. Denisov ${ }^{1,2}$, I.G. Gachev ${ }^{1}$, A.A. Bogdashov ${ }^{1}$, S.V. Mishakin ${ }^{1}$, \\ V.N. Manuilov ${ }^{1,2}$, V.I. Belousov ${ }^{1}$, D.I. Sobolev ${ }^{1}$, E.V. Sokolov ${ }^{1,3}$, E.A. Soluyanova ${ }^{1,3}$, E.M. Tai ${ }^{1,3}$ \\ ${ }^{1}$ Institute of Applied Physics, Russian Academy of Sciences, Nizhny Novgorod, Russia, samsonov@appl.sci-nnov.ru \\ ${ }^{2}$ Nizhny Novgorod State University, Russia \\ ${ }^{3}$ Gycom Ltd., Nizhny Novgorod, Russia
}

\section{Abstract}

A brief review of research activity on gyrotron traveling-wave tube amplifiers (gyro-TWTs) with helically corrugated waveguides developing by the Institute of Applied Physics and GYCOM (Nizhny Novgorod, Russia) will be presented.

\section{Introduction}

The gyrotron traveling wave tube (gyro-TWT) is known as a broad-frequency-band variety of gyrotrontype amplifiers having potential for production of the highest average or continuous-wave $(\mathrm{CW})$ power in the millimeter wavelength range [1] and therefore it is attractive as a microwave source for a number of applications such as radars, telecommunication and some other.

Since 1996 we are developing a concept of a gyroTWT that is based on the use of a helically corrugated waveguide that radically changes the dispersion of the modes of a circular waveguide [2]. The operating helicalwaveguide eigenmode has sufficiently high and almost constant group velocity at zero axial wavenumber which enables broadband operation of the helical-waveguide gyro-TWT with minimum sensitivity to electron velocity spread [3]. A number of experiments have proved the main theoretical predictions and advantages of gyroTWTs of this type [4-6].

\section{Ka-band application-oriented Gyro-TWTs}

Since 2009 eleven tubes were manufactured by IAP and GYCOM Ltd., tested and shipped to customers. Parameters of the experimental prototypes for those tubes are summarized in the Table.
Main experimental parameters of Ka-band application-oriented gyro-TWTs

\begin{tabular}{|l|c|c|}
\hline \multicolumn{1}{|c|}{ Parameter } & $\begin{array}{c}\text { Pulsed } \\
\text { tube }\end{array}$ & $\begin{array}{c}\text { CW } \\
\text { tube }\end{array}$ \\
\hline Accelerating voltage (kV) & 70 & 40 \\
\hline Retarding voltage (kV) & 25 & 20 \\
\hline Beam current (A) & 10 & 1.5 \\
\hline Interaction B-field (T) & 0.68 & 0.65 \\
\hline Magnet power consumption (kW) & 25 & 22 \\
\hline $\begin{array}{c}\text { Maximum output power (kW): } \\
\text { pulsed } \\
\text { average }\end{array}$ & 160 & 7.7 \\
\hline -1dB bandwidth (GHz) & 10 & 7.7 \\
\hline -3dB bandwidth (GHz) & 2.4 & 2.1 \\
\hline Saturated gain (dB): & $>2.7$ & 2.6 \\
at the band center & 23 & 26 \\
at the band sides & 20 & 19 \\
\hline Pulse duration & 100 us & hours \\
\hline
\end{tabular}

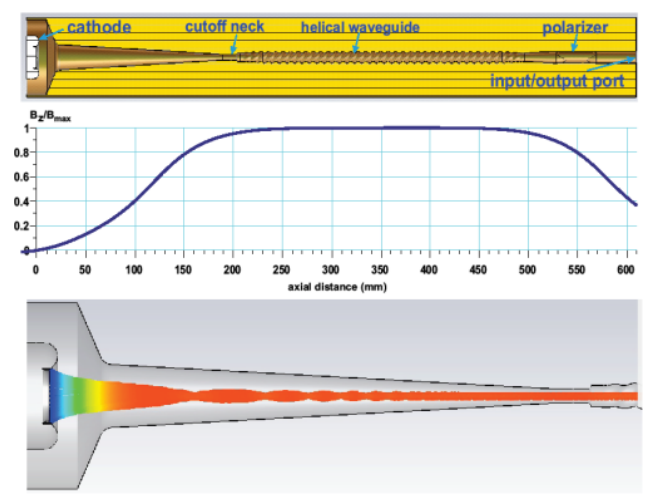

Fig. 1. CST model for simulation of a gyro-TWT from cathode to almost collector: whole geometry, B-field axial distribution and the gun part with particles' trajectories

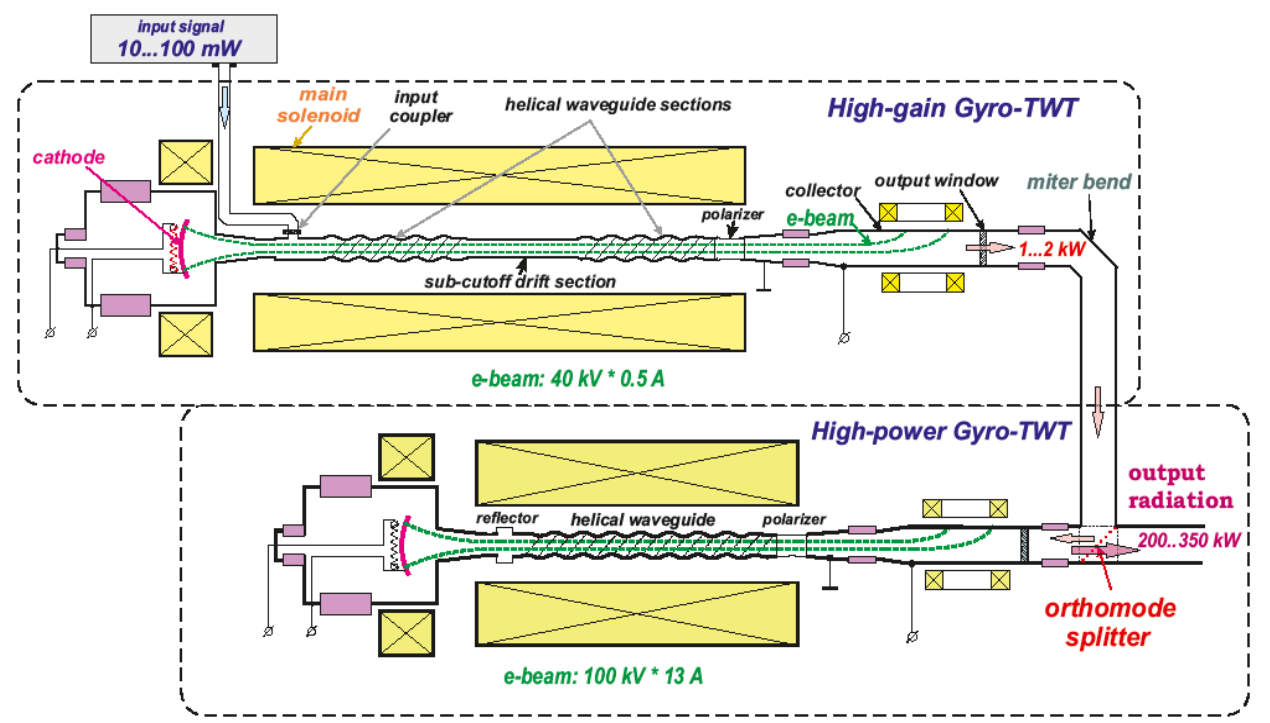

Fig. 2. Schematic view of cascade of two helically corrugated waveguide (HCW) gyro-TWTs 
Due to their operation at the second cyclotron harmonic these Ka-band gyro-TWTs used relatively low magnetic fields which were generated by nonsuperconducting magnets with reasonable power consumption. Since no highly absorbing materials were used in the interaction circuits, these amplifiers possessed relatively low gain to avoid the reflection-induced oscillation therefore mid-power preamplifiers were needed to ensure the drive-saturated regimes.

Recently a new microwave system for feeding and extracting the radiation to and from a gyro-TWT through one oversized window was suggested and experimentally verified $[7,8]$ which along with significant simplification of the circuit allows principal breakthrough in the power for short millimeter waves. An implementation of this method in Ka-band can make production costs of the gyro-TWTs comparable with those for technological gyrotrons with powers of tens kilowatts.

Computer modeling of almost whole device (Fig.1: only a large-volume collector part is not included) ensures high reliability of the design and predicted behavior of the system at various experimental conditions. Basing on this modeling and previous experience a "technological" CW gyro-TWT capable for amplification of a $20-\mathrm{W}$ $30-\mathrm{GHz}$ drive signal to $10 \mathrm{~kW}$ with $1 \mathrm{GHz}-3-\mathrm{dB}$ instantaneous bandwidth or $5 \mathrm{~kW}$ with $2 \mathrm{GHz}$ bandwidth was designed with moderate requirements to the power supplies $(25 \mathrm{kV} / 2 \mathrm{~A}$ for the electron beam and $15 \mathrm{~kW}$ for the magnet).

\section{Actual trends}

The actual topics of research on the gyro-TWT are as follows: a cascade of two tubes ensuring the highest gain and output power in W band (Fig. 2) [9]; various microwave systems for inputting and outputting the radiation to and from a tube through one window [7, 8, 10]; tubes operating at the third cyclotron harmonic [11]; tubes prospective for DNP-NMR spectroscopy $(260 \mathrm{GHz})$ [12]; tubes generating periodical sequences of ultrashort phasecoherent pulses [13].

Acknowledgements. Works mentioned in this review were supported by Federal Agency of Scientific Organizations under project 0035-2014-0023 (Sect.I), the Russian Science Foundation under Grant 16-19-10332 (Sect.II), Russian Academy of Science under Program 0035-2015-0007 (Sect.II), the Russian Science Foundation under Grant 16-42-01078 (Sect.II).

\section{References}

1. Thumm, M.K. State-of-the-Art of High Power GyroDevices and Free Electron Masers, Update 2015 // KIT Scientific Reports 7717. KIT Scientific Publishing.
2. Denisov, G.G. and Cooke, S.J. New microwave system for a gyro-TWT // Digest 21st Int. Conf. on Infrared and Millim. Waves, 1996, P.AT2.

3. Denisov, G.G., Bratman, V.L., Phelps, A.D.R., Samsonov, S.V. Gyro-TWT with a Helical Operating Waveguide: New Possibilities to Enhance Efficiency and Frequency Bandwidth // IEEE Trans. on Plasma Sci. 1998. V. 26, No. 3. P. 508-518.

4. Bratman, V.L., Cross, A.W., Denisov, G.G., He, W., Phelps, A.D.R., Ronald, K., Samsonov, S.V., Whyte, C.G. and Young, A.R. High-Gain Wide-Band Gyrotron Traveling Wave Amplifier with a Helically Corrugated Waveguide // Phys. Rev. Letts. 2000. V. 84, No. 12. P. 2746-2749.

5. Bratman, V.L., Denisov, G.G., Samsonov, S.V., Cross, A.W., Phelps, A.D.R., He, W. High-efficiency wideband gyroTWTs and gyro-BWOs with helically corrugated waveguides // Radiophys. Quantum Electron., 2007. V. 50, No. 2. P. 95-107.

6. Samsonov, S.V., Gachev, I.G., Denisov, G.G., Bogdashov, A.A., Mishakin, S.V., Fiks, A.S., Soluyanova, E.A., Tai, E.M., Dominyuk, Y.V., Levitan, B.A., Murzin, V.N. Ka-band Gyrotron Traveling-Wave Tubes with the Highest ContinuousWave and Average Power // IEEE Trans. Electr. Dev. 2014. V. 61, No. 12. P. 4264-4268.

7. Denisov, G.G., Samsonov, S.V., Mishakin, S.V., Bogdashov, A.A. Microwave system for feeding and extracting power to and from a gyrotron traveling-wave tube through one window // IEEE Electron Device Letters. 2014. V. 35, No.7. P. 789-791.

8. Samsonov, S.V., Bogdashov, A.A., Denisov, G.G., Gachev, I.G., Mishakin, S.V. Proof-of-Principle Experiment on High-Power Gyrotron Traveling-Wave Tube with a Microwave System for Driving and Extracting Power Through One Window // IEEE Microwave and Wireless Components Letters. 2016. V. 26, No. 4. P. 288-290.

9. Samsonov, S.V., Bogdashov, A.A., Denisov, G.G., Gachev, I.G., Mishakin, S.V. Cascade of Two W-Band HelicalWaveguide Gyro-TWTs with High Gain and Output Power: Concept and Modeling // IEEE Trans. on El. Dev., 2017. V.64, No.3. P. 1297-1301.

10. Mishakin, S.V., Samsonov, S.V., Sobolev, D.I., Gashturi, A.P., and Denisov, G.G. Radiation Input/Output System of a Broadband W-band Gyrotron Traveling-Wave Amplifier // Proc. of 41st Int. Conf. on Infrared, Millimeter and Terahertz Waves, Copenhagen, Denmark, 2016, art. no. 7758386.

11. Mishakin, S.V., Samsonov, S.V., and Denisov, G.G. A Helical-Waveguide Gyro-TWT at the Third Cyclotron Harmonic // IEEE Trans. on Electron Devices. 2015. V.62, No.10. P. 3387-3392.

12. Mishakin, S.V., Bogdashov, A.A., Denisov, G.G., Samsonov, S.V., Kalynov, Yu.K., and Manuilov, V.N. Secondharmonic $260-\mathrm{GHz}$ gyrotron traveling-wave amplifier with helically corrugated waveguide // Proc. of 9th Int. Workshop "Strong Microwaves and Terahertz Waves: Sources and Applications", Nizhny Novgorod - Perm - Nizhny Novgorod, Russia, July 24-30, 2014, P. 231-232.

13. Ginzburg, N.S., Denisov, G.G., Vilkov, M.N., Sergeev, A.S., Zotova, I.V., Samsonov, S.V., Mishakin, S.V. Generation of trains of ultrashort microwave pulses by two coupled helical gyro-TWTs operating in regimes of amplification and nonlinear absorption // Physics of Plasmas. 2017. V.24, No.2. art. no. 023103. 